\title{
Sobre jogos de (des)montar: Covid-19 e Atenção Primária à Saúde
}

\section{I ${ }^{1}$ Ana Carolina Maia, ${ }^{2}$ Rafael Agostini, ${ }^{3}$ Rogerio Lopes Azize I}

\author{
${ }^{1}$ Instituto de Medicina Social, Universidade do Estado do Rio de Janeiro. Rio de Janeiro-RJ, Brasil (costamaia.anacarolina@gmail.com). \\ ORCID; 0000-0002-4144-0526 \\ ${ }^{2}$ Instituto Fernandes Figueira, Fundação Oswaldo Cruz. Rio de Janeiro-RJ, Brasil (rafael.agostini.vbg@gmail.com). \\ ORCID: 0000-0001-8071-9362 \\ ${ }^{3}$ Instituto de Medicina Social, Universidade do Estado do Rio de Janeiro. Rio de Janeiro-RJ, Brasil (rogerioazize@hotmail.com). \\ ORCID: 0000-0002-1876-8507
}

Recebido em: 05/06/2020

Aprovado em: 23/06/2020

Revisado em: 27/06/2020

DOI: http://dx.doi.org/10.1590/S0103-73312020300314

Pouco depois das primeiras cenas da pandemia de Covid-19 no Brasil, assistimos pela televisão a um tipo de comentário pouco comum: o Ministro da Saúde destacou naquele momento o papel de agentes comunitários de saúde (ACS) no combate ao desastre que em parte se anunciava, em parte se negava, dentro do mesmo governo. Personagens conhecidos em nossas comunidades mais pobres, talvez menos entre a população que faz uso da saúde complementar, os ACS aparecem como "infantaria", "front de combate" e saber estratégico, seguindo uma certa linha das metáforas de guerra que povoam a retórica do atual Governo Federal.

O ministro que fazia estes anúncios não tinha qualquer vínculo com a construção histórica do Sistema Único de Saúde (SUS), muito pelo contrário; enquanto deputado, sempre orientou sua atuação parlamentar para seu esvaziamento. Apesar disso, com sua deposição, o colete do SUS não seria mais vestimenta obrigatória na comunicação entre Ministério da Saúde e a população a partir do segundo Ministro da Saúde durante a pandemia, com passagem meteórica pela pasta. Enquanto este texto se escreve, aliás, sequer a figura de um ministro parece obrigatória. Temos um interino militar sem qualquer formação na área enquanto os números de óbitos e casos sobem, em uma ironia mortal: a presidência falava na possibilidade de 
um isolamento vertical, e o que temos é uma linha quase vertical em gráficos que traduzem mortes em números.

Em resposta à chamada da Physis para pensar o contexto e as consequências de uma política de desmonte da capacidade operacional do SUS e seus impactos sobre a pandemia, propomos uma reflexão sobre o que chamamos aqui, não sem ironia, jogos de (des)montar. Por um lado, sublinhar opçóes políticas que podem ser traduzidas em números negativos (demissões, desmonte de equipes, redução da cobertura do modelo de equipes de Saúde da Família); por outro, salientar experiências de pesquisas de campo que mostram a potência desse modelo público para a saúde, mesmo em resposta a um cenário de transformação rápida, como a chegada maciça de refugiados ou a responsabilização pela assistência às pessoas vivendo com HIV/Aids (PVHA), por exemplo.

Vamos relacionar os números nefastos da pandemia no município do Rio de Janeiro à diminuição da cobertura territorial da Estratégia de Saúde da Família (ESF), que passou de 70\% para 55\% (SMS, 2018a) nos últimos anos. E, a partir disso, discutir as potências do SUS para transtornar interesses de matriz neoliberal e disputar "coraçóes e mentes na defesa de um projeto nacional de desenvolvimento popular, soberano e solidário” (AGOSTINI; CASTRO, 2020, p. 185).

A partir de dados de campo de duas pesquisas conduzidas em unidades básicas de saúde (UBS) da cidade, procuraremos relacionar a especial capilaridade da Atenção Primária à Saúde (APS), com sua atuaçáo centrada no território, à sua capacidade de interagir com os contextos comunitários dos usuários. Essa característica torna esse nível de atenção imprescindível no controle da multiplicação desenfreada de casos da Covid-19. Em face de um novo agente que a ciência apenas começa a conhecer, as recomendações dos especialistas devotos do método científico e dos ensaios clínicos randomizados têm convergido em uma direção única: o distanciamento social e a higienização das mãos e de objetos.

$\mathrm{O}$ vírus chegou ao Brasil pelas classes médias e altas que voltavam da Europa e rapidamente caminhou para as periferias das grandes cidades e cidades do interior, desnudando uma verdade há muito conhecida pelos cientistas sociais, sanitaristas e epidemiologistas: o vírus circula nas fissuras da sociedade, atingindo mais agudamente os pobres e vulnerabilizados (PARKER et al., 2015) e evidenciando a distribuição desigual da precariedade (BUTLER, 2015). 


\section{Uma crise em quatro tempos}

A vida do povo brasileiro já não era das mais fáceis mesmo antes da Covid-19 e a emergência sanitária foi, afinal, uma quarta demão em uma grave crise que nos afligia anteriormente e se transformou em uma "tempestade perfeita". Para circunscrever o que entendemos como as três primeiras camadas, recuperamos a definição proposta por Agostini et al. (2019), para quem a crise é polifônica, multidimensional e intersecciona - a partir de questôes globais e especificidades locais - sentidos sociais, políticos e econômicos.

Seguindo no diálogo com os autores, é preciso ponderar que as chamadas "jornadas de junho" eclodiram em 2013 em um contexto em que os indicadores socioeconômicos e políticos nacionais estavam em suas melhores marcas históricas. Foram, assim, a despeito da sua intencionalidade, instrumentalizadas como baláo de ensaio da novelização de operaçóes policiais que as seguiram e que foram responsáveis por destruir o já combalido tecido produtivo nacional. A consequência foi a deterioração de nossos indicadores macroeconômicos sem a qual o "grande acordo nacional, com o Supremo, com tudo" jamais teria ganho adesão popular.

Com o golpe de 2016, o neoliberalismo ascendeu ao Palácio do Planalto com uma agenda mais privatista e entreguista do que aquela que fora derrotada em 2014. A ascensão de Michel Temer legitimou o desmonte do sistema de proteção social brasileiro, passando mormente pelo SUS. Nesse contexto, a Emenda Constitucional 95, que congela por um par de décadas investimentos sociais, acaba por desfinanciar um sistema de saúde já historicamente subfinanciado (FUNCIA, 2017). Concomitantemente, as instituiçóes permaneceram assentindo - quando não capitaneando - as chicanas jurídico-políticas de perseguição de uns e de blindagem de outros, fraudando a soberania popular e alimentando "o ódio como política" em diversas searas, como é possível ver nos artigos da coletânea organizada pela Profa. Esther Solano (2018). O resultado foi, na esteira de um movimento internacional, a vitória nas urnas de uma agenda que rompe com pactos civilizatórios mínimos, como a defesa, ao menos do ponto de vista discursivo, da alteridade, da liberdade de imprensa, dos consensos científicos e da própria democracia como valor. E que, ao mesmo tempo, promove o aprofundamento das fissuras nas relaçôes interpessoais e a autofagia das instituições. 
É nesse cenário que no final de fevereiro de 2020 o primeiro caso de Covid-19 é diagnosticado no Brasil, rapidamente acompanhado pela ausência de testagem, leitos hospitalares e insumos de proteção para os trabalhadores do sistema de saúde e para a população em geral. São necessários quase três semanas e o primeiro óbito para que as primeiras medidas de distanciamento social sejam adotadas por governadores e prefeitos. O Presidente da República, por sua vez, insiste na falsa dicotomia entre salvar o povo brasileiro ou a economia nacional. Em seus discursos, contraria a Ciência, reduz a pandemia a uma "gripezinha", incita a utilização de drogas sem eficácia comprovada, defende a substituição das medidas de contenção sanitária por um suposto "isolamento vertical" - este uma técnica controversa e ineficaz, segundo os epidemiologistas. Ademais, acusa governadores e prefeitos de promoverem um "confinamento em massa", invertendo o sentido original da expressão, que se refere a condiçóes penitenciárias no Brasil. ${ }^{1}$ Ao mesmo tempo, o auxílio emergencial e o socorro aos pequenos e médios empresários que possibilitam condiçóes materiais de respeito às regras de distanciamento ignoram as especificidades locais, são lentos, pouco transparentes e têm causado eles próprios as aglomeraçóes que pretendiam evitar.

Com disseminação bem mais fácil que o vírus da gripe, a Covid-19 tem manifestaçóes leves e não é grave para a maior parte dos infectados. Para uma minoria, contudo, a infecção requer internaçóes, sendo uma pequena porcentagem delas em UTI. No entanto, além da rede de retaguarda hospitalar e ambulatorial já ser um gargalo histórico da organização da rede de saúde desde a operacionalização do SUS (CECILIO, 2001), nenhum país do mundo possui leitos para tantas pessoas. Isso nos colocou na situação de precisar montar grandes estruturas - como os hospitais de campanha, cuja rápida construção já se encontra sob suspeita de desvio de verbas - em meio ao desmonte em curso no pós-golpe. Em certo momento, a cidade do Rio de Janeiro apresentou uma das maiores taxas de mortalidade pela Covid-19 do país, bastante acima da média nacional, que já não é irrisória (BRASIL, 2020).

\section{Da "reforma" neoliberalizante ao desmonte da APS: paradoxos à carioca}

Em uma Clínica da Família que repentinamente começou a receber migrantes congoleses - refugiados e solicitantes - que eram muito difíceis de serem acessados na periferia da cidade de Rio de Janeiro, a porosidade da APS às especificidades 
locais dos usuários foi fator decisivo para que um fluxo de cadastro e atendimento dessa população fosse criado (MAIA; AZIZE, 2020). Um exemplo foi a participação do gerente e profissionais da clínica em um culto dominical dos refugiados para convidá-los a se cadastrar na unidade, a despeito da não adscrição territorial, na medida em que derrubar quaisquer barreiras de acesso e mapear e assistir esta população que chegava extremamente vulnerabilizada à cidade era um imperativo ético-político naquele momento. Eis aqui a primeira demonstração da ESF como tecnologia competente para responder a contextos de mudanças rápidas.

Em outra Clínica da Família na regiáo central da cidade, uma pesquisa de doutoramento ainda em curso sobre a descentralização da assistência às PVHA ${ }^{2}$ tem evidenciado que, apesar dos desafios referentes ao sigilo do diagnóstico, a ESF amplia o acesso à testagem e ao tratamento daquelas pessoas que náo querem, não podem, ou não conseguem se deslocar - por questóes físicas, econômicas ou temporais - para os serviços especializados. A criação de vínculo almejada neste nível de atenção também vem aparecendo como elemento definidor do incremento da adesão ao tratamento no caso de grupos mais vulnerabilizados como pessoas em situação de rua ou em extrema precariedade econômica, por exemplo. A interação com as ACS, aliás, pela possibilidade de se efetivar repetidamente, tem papel de destaque nesse processo. Eis, portanto, outra potência evidente da ESF - desta vez, na lida com populaçóes atingidas por uma epidemia.

Ambas as pesquisas apontaram, assim, a despeito dos desafios e contradiçóes, a capacidade ímpar da ESF de interagir com os contextos comunitários e, portanto, a potência de sua atuação na assistência às populaçôes vulnerabilizadas. No município do Rio de Janeiro, onde tais pesquisas foram realizadas, a ESF passou por uma franca expansão, saindo de 3,5\% de cobertura de 2008 para 70\% em 2016 (SORANZ et al., 2016). Isso se deu a reboque de um grande paradoxo que, por um lado, levou o acesso à saúde para uma populaçáo historicamente desassistida, fazendo com que as Clínicas da Família adentrassem a vida e o imaginário da população carioca. Por outro, esse processo de expansão enfraqueceu relaçôes trabalhistas desses profissionais da saúde que atuam na APS, já que só foi possível sob a égide de uma lógica privatista que permitiu altos salários, mas frágeis vínculos trabalhistas, o que acabou submetendo profissionais e usuários a um modelo de gestão fortemente marcado pelo gerencialismo, muito mais preocupado com a gestão dos serviços do que efetivamente do cuidado (MELOet al., 2018). 
Focada fundamentalmente no território e no cuidado "ao longo da vida" e apesar de suas contradiçóes, a ESF é a política mais capilarizada do país. Como pudemos perceber durante as pesquisas que abrem esta seção, as visitas domiciliares de profissionais da saúde, guiados por ACS, abriram um flanco pelo qual o setor saúde pôde chegar a populações que antes dela só eram vistas pela polícia, a milícia e os pastores. A atuação dessas profissionais se destaca e são a "porta de entrada da porta de entrada" da rede de saúde, sem os quais a população do território não seria acessada, já que é o ACS "quem sinaliza tudo pra gente [...], que vai pra rua, que cava, que acha” (MAIA, 2018). Essas trabalhadoras, por óbvio, também têm papel estratégico no modelo de pandemia: são as profissionais que, mesmo sem insumos, conhecem as dificuldades dos moradores de periferias em cumprir o distanciamento social e podem incidir sobre elas.

O acesso adequado à ESF é ponto pacífico para a melhora da saúde das populações a ponto de existir na literatura programática ministerial a relação das Condições Sensíveis à Atenção Primária. ${ }^{3}$ No entanto, desde 2017, o prefeito Marcelo Crivella vem submetendo a APS a uma chamada "reorganização" que, na prática, descredenciou 184 equipes de Saúde da Família, 55 equipes de Saúde Bucal e extinguiu sumariamente 1.400 empregos (SMS, 2018b). O encolhimento da mais capilarizada política de saúde existente no país já seria um problema em situaçôes normais. Ocorre que as condiçôes para as quais o contato com a ESF é diferencial são justamente aquelas de risco acrescido para os agravos da Covid-19. Será este nível de atenção também o mais procurado para as demandas reprimidas do pós-pandemia, e para mobilização no eventual caso de uma imunização do povo brasileiro. Seu desmantelamento, acompanhado de uma pandemia desta monta, foi, assim, uma sinistra e assassina combinação - como vaticina a professora Mariana Nogueira (2020), “o vírus é o agente etiológico da doença, mas não do caos".

\section{Potencialidades em tempos de crise: o SUS como trincheira}

Como vimos, estamos atravessando a mais grave crise sanitária do último século, potencializada, no caso brasileiro, por uma crise que traz também dimensões sociais, políticas e econômicas, e por um franco desmonte da capacidade operacional do SUS no momento em que o povo brasileiro mais precisa dele. Somos, assim, levados ao tabuleiro dos mórbidos jogos de (des)montar, em que é preciso montar em meio ao 
desmonte em curso. Os números da pandemia no município do Rio, como vimos, são alarmantes e conseguem ser piores do que a média nacional, o que, em alguma medida, foi influenciado pelo processo de desmantelo da reconhecida APS carioca. Por outro lado, nossas pesquisas vêm mostrando que, apesar da necessidade de enfrentar desafios, a organização por áreas e microáreas da APS se configura como modelo diante das transformaçôes rápidas e características de uma pandemia. Isso requer, no entanto, que tornemos pública a potência do modelo diante da ameaça do desmantelo e precarização absoluta, com a possibilidade inclusive da uberização dos profissionais da ESF a partir de plantôes coringas decorrentes da "reorganização" do prefeito Crivella.

Em um contexto no qual a pandemia eleva a discussão sobre o tamanho do Estado e do mercado a uma das mais importantes que devemos travar no momento, a racionalidade neoliberal selvagem vem destruindo justamente o sistema de proteção social que se constitui como única separação entre a morte e o destino povo brasileiro - entre se a nação estará na vanguarda do mundo na resposta à Covid-19 ou se voltará a ser pária do mundo multipolar.

Nesse contexto, a ESF se transforma em uma trincheira importante em relação a esses jogos perigosos de montar e desmontar a saúde pública. As pesquisas de campo mencionadas aqui dão conta de que não foi sem encontrar resistência que as equipes de saúde foram descredenciadas; com frequência, os usuários dos serviços se juntaram às suas ACS para protestar contra demissóes sumárias; em alguns casos, profissionais foram readmitidas. A potência de haver Estado no local onde o usuário vive, estuda e ora permite que esse sujeito exerça seu direito à saúde e se enxergue em um projeto de país que o inclua.

Reforçamos aqui a potencialidade da APS como ponta de lança de um projeto ético-político no qual o Estado é um agente de diminuição das desigualdades e garantidor de direitos. Os dados de pesquisa corroboram, pois, a evidência nada misteriosa de que a política de saúde mais capilarizada do país é um atalho imprescindível para mecanismos que poderiam prevenir mortes que se aglomeram e números que se multiplicam.

\section{Referências}

AGOSTINI, R. et al. A resposta brasileira à epidemia de HIV/Aids em tempos de crise. Ciência ¿ Saúde Coletiva, v. 24, n. 12, p. 4599-4604, 2019. 
AGOSTINI, R.; CASTRO, A. O que pode o Sistema Único de Saúde em tempos de necropolítica neoliberal? Saúde em Debate, Rio de Janeiro, v. 43, n. esp. 8, p. 175-188, dez. 2019.

BRASIL. Painel Coronavirus. Disponível em: https://covid.saude.gov.br/. Acesso em: 4 jun. 2020. BUTLER, J. Quadros de guerra: quando a vida é passível de luto. Rio de Janeiro: Civilização Brasileira, 2015.

CECILIO, L. C. O. As necessidades de saúde como conceito estruturante na luta pela integralidade e equidade na atenção. In: PINHEIRO, R.; MATTOS, R. A. (Orgs.). Os sentidos da integralidade na atenção e no cuidado à saúde. Rio de Janeiro: IMS-ABRASCO, 2001. p. 113-126.

FUNCIA, F. Efeitos negativos da emenda constitucional 95/2016 sobre a execução orçamentária e financeira de 2017 do Ministério da Saúde. Disponível em: <https://www.cmb.org.br/cmb/index. $\mathrm{php/noticias/2347-efeitos-negativos-da-emenda-constitucional-95-2016-sobre-a-execucao-}$ orcamentaria-e-financeira-de-2017-do-ministerio-da-saude> Acesso em: 2 jun. 2020.

KLEMPERER, V. A linguagem do Terceiro Reich. Rio de Janeiro: Editora Contraponto, 2019.

MAIA, A. C. Saúde em trânsito: o fluxo de assistência aos refugiados na atenção primária em saúde no município do Rio de Janeiro. Dissertação (Mestrado em Saúde Coletiva) - Instituto de Medicina Social, Universidade do Estado do Rio de Janeiro, 2018.

MAIA, A. C.; AZIZE, R. L. Saúde nas margens: dilemas da territorialidade da Atenção Primária em Saúde no cuidado aos refugiados no município do Rio de Janeiro, Brasil. Ciência \& Saúde Coletiva, v. 25, n 5, p. 1789-1797, 2020.

MELO, E. A.; MATTOS, R. A. Gestão do Cuidado e Atenção Básica: controle ou defesa da vida? In: MENDONÇA, M. H. M. et al. (Orgs.). Atenção Primária à Saúde no Brasil: conceitos, práticas e pesquisa. Rio de Janeiro: Fiocruz, 2018, v. 1, p. 95-116.

NOGUEIRA, M. Precisamos falar das condiçôes de vida. RADIS, Fiocruz. Rio de Janeiro, jun. 2020. Disponível em: <https://radis.ensp.fiocruz.br/index.php/home/entrevista/precisamosfalar-das-condicoes-de-vida>. Acesso em: 2 jun. 2020.

PARKER, R.; GROTZ, F. O retorno do vírus ideológico. Boletim da Associação Brasileira Interdisciplinar de AIDS. Rio de Janeiro, n. 60, jun. 2015.

SECRETARIA MUNICIPAL DE SAÚDE. Grupo de trabalho do Conselho Municipal de Saúde para análise da "proposta de reorganização" da Atenção Primária à Saúde da SMS. Relatório Parcial. $1^{a}$ versão. Rio de Janeiro, 2018a. Disponível em: <http://www.ensp.fiocruz. br/portal-ensp/informe/site/materia/detalhe/45172>. Acesso em: 4 jun 2020.

. Reorganização dos serviços de atenção primária à saúde: estudo para otimização de recursos. Rio de Janeiro, 2018b. Disponível em: <http://www.ensp.fiocruz.br/portal-ensp/ informe/site/arquivos/anexos/e724fbbea2e73dc2d89630de33a2ff170ed967ec.PDF>. Acesso em: 4 jun 2020. 
SOLANO, E. (Org.). O ódio como politica: a reinvenção das direitas no Brasil. São Paulo: Boitempo, 2018.

SORANZ, D. et al. Eixos e a Reforma dos Cuidados em Atenção Primária em Saúde (RCAPS) na cidade do Rio de Janeiro, Brasil. Ciência \& Saúde Coletiva. Rio e Janeiro, v. 21, n. 5, p. 13271338, 2016.

\section{Notas}

${ }^{1}$ Vale aqui mencionar que o deslizamento de sentido aplicado a algumas expressôes conhecidas é uma técnica algo comum neste governo, vide os usos por vezes propostos de termos como "liberdade de expressão" e "direitos humanos". Para um debate mais refinado sobre regimes políticos modificando o sentido de determinadas expressốes, quase como uma nova linguagem, ver Klemperer (2019).

${ }^{2}$ Conduzida por Rafael Agostini sob orientação da Profa Ivia Maksud no âmbito do doutoramento em Saúde Coletiva (PPGSCM/IFF/FIOCRUZ).

${ }^{3}$ A expansão da Atenção Primária à Saúde em todo o país até 2016, sobretudo a partir de indução financeira do Governo Federal, fez com o que a rede de saúde tenha aumentado sua cobertura de forma significativa. Em situações em que a APS não é resolutiva, cresce a demanda para internaçôes hospitalares, um gargalo histórico da nossa rede regionalizada de serviços. A relação das condições sensíveis à atenção primária é um indicador que busca medir a efetividade da APS ao acompanhar internaçóes hospitalares advindas de agravos de saúde que poderiam ter sido evitados na atenção primária. 